\title{
Acute Myocardial Infarction with Bundle Branch Block (Rbbb or Lbbb) - Clinical Characteristics, Complications \& Prognostic Significance - A Hospital Based Study
}

\author{
Dr. Archana Gupta ${ }^{1}$,Dr. Sachin Shelke ${ }^{2}$
}

\begin{abstract}
The occurrence of bundle branch block in acute myocardial infarction is important because it indicates that infarction may be extensive and may result in cardiac failure or death; however, the presence of bundle branch block is also important because it indicates seriously jeopardized AV conduction which could result in sudden extremely slow heart rates or asystolic arrest.

The aim of the study was to study clinical characteristics in patients of acute coronary syndrome with bundle branch block and to assess the association of bundle branch block with major cardiovascular events or complications and to determine in-hospital mortality. The study was done on patients of acute myocardial infarction (MI) admitted between April 2012 to Nov. 13 in the coronary unit of J.A.H., Gwalior .

Informed and written consent was taken from all patients before enrolling this work. The inclusion criteria included those patients admitted within 48 hrs of onset of symptoms with bundle branch block on the admission ECG and new onset bundle branch block during hospital stay Study excluded patients with previous history of documented bundle branch block.

The statistically significant findings of the study included more common incidence of anterior wall infarct over inferior, right bundle branch block over left bundle branch block, right bundle branch block in males and in patients of age less than 60 years. Mortality was higher in patients with anterior wall MI associated with finding of Left bundle branch block.
\end{abstract}

Keyword: Bundle branch block, myocardial infarction

\section{Introduction}

Acute coronary syndrome, being a leading cause of morbidity and mortality, has become a major public health problem. In MI, occlusion of coronary arteries at differentl levels affects the conduction system of heart leading to various type of blocks. Previous studies pertaining to patients with AMI and BBB, left and right (LBBB \& RBBB) at hospital admission were both in prethrombolytic and thrombolytic era and reported a overall poor prognosis and high risk for short term death., ${ }^{2,9,12}$

Complete BBB, left or right, on electrocardiogram at presentation occurs in a wide range of $8 \%$ to $23 \%$ of patients with AMI and represents an independent important predictor of in hospital complications and poor survival. ${ }^{1-13}$ New BBB usually expresses a large infarction, frequently accompanied by heart failure, complete AV block, arrhythmia and high mortality rates. ${ }^{10}$ In the present study, an attempt has been made to assess clinical characteristics and short term prognostic significance of BBB in acute MI, with respect to its location, time of appearance and association with complications.

\section{Material And Method}

The study was done on patients of acute MI admitted between April 2012 to Nov. 13 in the coronary unit of J.A.H., Gwalior with following inclusion and exclusion criteria. Informed and written consent was taken from all patients before enrolling this work. The cases which were included in our study were patients admitted within $48 \mathrm{hrs}$ after the onset of symptoms with BBB on the admission ECG and new onset BBB during hospital stay in subsequent ECG.The patients with previous history of documented BBB were excluded from study .

\footnotetext{
Methodology

After the admission the standard 12 lead ECG was recorded and following criteria was used to define BBB: LBBB

1. QRS duration $>120 \mathrm{~ms}$ in the presence of normal sinus or supraventricular rhythm

2. QS or RS complex in lead V1

3. Broad or notched $\mathrm{R}$ waves in leads V5 and V6, or an RS pattern

4. $\mathrm{R}$ peak time $>0.006 \mathrm{~s}$ without $\mathrm{Q}$ waves in lead I, V5 or V6 RBBB

1. QRS duration > $120 \mathrm{~ms}$ in the presence of normal sinus or supraventricular rhythm.
} 
2. R or RSR complex in lead V1

3. RS in leads I, aVL, V5, V6, with a prolonged, shallow $\mathrm{S}$ wave.

BBB was classified as transient when there was no BBB present at time of hospital discharge and permanent when the patient either died or was discharged with BBB present. Further transient block was subdivided into three categories of their duration (1-6 hrs, 6-24 hrs, 1-6 days) for ease of data collection. And permanent block was subdivided into two categories of persistent until discharge and persistent until death.

The site of infarction was noted according to the evolutionary ST-T wave changes in the appropriate leads and were categorized as anterior and inferior as main for data analysis. The worst class of heart failure of each patient was obtained by their clinical status on admission and these were designated in classes I-IV as defined by killip and kimball. In hospital mortality is defined as death occurring during hospital stay.

\section{Followup}

All the patients recruited for study followed up, from the time of admission to either death or 30 days if possible.

\section{Statistical Analysis}

For statistical analysis $c^{2}$ test, Fisher's exact test, student's t-test are used. Graph pad software is used for calculating $\mathrm{p}$ value by $\mathrm{c}^{2}$ test and In Silico Software for calculating $\mathrm{p}$ value by Fisher's exact test and students $\mathrm{t}$ test. $95 \%$ confidence interval was used, $p$ value higher than 0.05 were considered non-significant.

\section{Observations}

The present study is a hospital bound study, 100 patients of acute myocardial infarction with bundle branch block were included considering inclusion and exclusion criteria.

Table No. 1 Age distribution with sex

\begin{tabular}{|l|l|l|l|l|l|}
\hline \multirow{2}{*}{ Age in yrs } & Male & Female & Total \\
\cline { 2 - 6 } & No. & \% & No. & \% & \\
\hline$<40$ & 5 & 6.57 & - & - & 5 \\
\hline $40-59$ & 32 & 42.10 & 3 & 12.50 & 35 \\
\hline $60-79$ & 33 & 43.42 & 19 & 79.16 & 52 \\
\hline$>80$ & 6 & 7.89 & 2 & 8.33 & 8 \\
\hline Total & 76 & 100 & 24 & 100 & 100 \\
\hline Mean \pm SD & $58.72 \pm 13.22$ & $64.83 \pm 8.77$ & $60.19 \pm 12.54$ \\
\hline
\end{tabular}

The majority of patients belonged to age group of 60-79 yrs with mean age of $60.19 \pm 12.54$. In study the total number of male patients are 76, with mean age of $58.72 \pm 13.22$. While females are 24 with mean age of $64.83 \pm 8.77$. Females (mean age $=64.38 \pm 8.77$ ) are older than males (mean age $58.72 \pm 13.22$ ) which is statistically significant $(\mathrm{p}=0.011)$.

Table No. 2 Sex wise distribution depending on location of infarct

\begin{tabular}{|l|l|l|l|l|l|}
\hline \multirow{2}{*}{ Sex } & Anterior & Inferior & p value \\
\cline { 2 - 6 } & No. & \% & No. & \% & \\
\hline Male $(\mathrm{n}=76)$ & 54 & 71.05 & 22 & 28.94 & $0.0002^{*}$ \\
\hline Female $(\mathrm{n}=24)$ & 17 & 70.83 & 7 & 29.16 & $0.0412^{*}$ \\
\hline Total $(\mathrm{n}=100)$ & 71 & 71 & 29 & 29 & $0.0001^{*}$ \\
\hline $\mathrm{c}^{2}=0.06$ and $\mathrm{p}$ value $=0.3069$ & \\
*
\end{tabular}

*statistically significant.

The anterior wall infarct is much common (71\%) compared to inferior wall infarct (29\%). In the study group anterior wall infarct is more common than inferior wall infarct, it is statistically significant $(\mathrm{p}=0.0001)$.

Table No. 3 Sex wise distribution according to type of BBB

\begin{tabular}{|l|l|l|l|l|l|}
\hline \multirow{2}{*}{ Sex } & \multicolumn{2}{l}{ RBBB } & LBBB & \multirow{2}{*}{ p value } \\
\cline { 2 - 5 } & No. & \% & No. & \% & \\
\hline Male $(\mathrm{n}=76)$ & 53 & 69.73 & 23 & 30.26 & $0.0006^{*}$ \\
\hline Female $(\mathrm{n}=24)$ & 16 & 66.66 & 8 & 33.33 & 0.102 \\
\hline Total $(\mathrm{n}=100)$ & 69 & 69.00 & 31 & 31.00 & $0.0001^{*}$ \\
\hline $\mathrm{c}^{2}=0.08, \mathrm{p}$ value $=0.77$ & $*$ statistically significant \\
\end{tabular}


RBBB is common $(69 \%)$ than LBBB $(31 \%)$ which is statistically found to be highly significant $(\mathrm{p}=0.0001)$. Incidence of RBBB in males $(69.73 \%)$ is more to that in LBBB $(30.26 \%)$ which is highly statistically significant ( $\mathrm{p}$ value $=0.0006$ ). The distribution of females is not found to be statistically significant.

Table No. 4 Age wise distribution according to type of BBB

\begin{tabular}{|l|l|l|l|l|l|}
\hline \multirow{2}{*}{ Age in yrs } & \multicolumn{2}{|l|}{ RBBB $(\mathbf{n}=\mathbf{6 9})$} & LBBB $(\mathbf{n}=\mathbf{3 1})$ & \multirow{2}{*}{ P value } \\
\cline { 2 - 5 } & No. & $\mathbf{\%}$ & No. & \% & \\
\hline$<40(\mathrm{n}=5)$ & 5 & 7.24 & 0 & 0 & $0.025^{*}$ \\
\hline $40-59(\mathrm{n}=35)$ & 27 & 39.13 & 8 & 25.80 & $0.0013^{*}$ \\
\hline $60-79(\mathrm{n}=52)$ & 31 & 44.92 & 21 & 67.74 & 0.165 \\
\hline$>80(\mathrm{n}=8)$ & 6 & 8.69 & 2 & 6.45 & 0.15 \\
\hline $\mathrm{c}^{2}=0.03, \mathrm{p}$ value $=0.8625$ \\
* statistically significant
\end{tabular}

Maximum number of RBBB patients belongs to 60-79 age group (44.92\%) and maximum (67.74\%) of LBBB patients belong to 60-79 age group. Patients of age $<60 \mathrm{yrs}$ is more commonly having RBBB than LBBB which is statistically found to be significant in our study ( $P$ value <0.05). Patients of older age group, of age $>60 y$ rs are having LBBB commoner than RBBB which is not found statistically significant.

Table No. 5 Association of site of infarct with BBB

\begin{tabular}{|l|l|l|l|l|}
\hline Site & RBBB $(\mathbf{n}=\mathbf{6 9})$ & LBBB $(\mathbf{n}=\mathbf{3 1})$ & Total & p value \\
\hline Anterior $(\mathrm{n}=71)$ & 40 & 31 & 71 & 0.28 \\
\hline Inferior $(\mathrm{n}=29)$ & 29 & 0 & 29 & $<0.0001 *$ \\
\hline
\end{tabular}

Most common is anterior wall MI with RBBB, (40\%) followed by anterior wall with LBBB (31\%) and the inferior wall MI with RBBB (29\%). It is found statistically significant that there is more common association of inferior wall MI with RBBB compared to that of with LBBB $(\mathrm{p}<0.0001)$.

Table No. 6 Comparison of Heart rate \& Blood pressure according to type of BBB

\begin{tabular}{|l|l|l|l|}
\hline & $\begin{array}{l}\text { RBBB } \\
(\mathbf{n = 6 9 )}\end{array}$ & $\begin{array}{l}\text { LBBB } \\
(\mathbf{n = 3 1})\end{array}$ & p value* $^{*}$ \\
\hline Heart rate (mean \pm SD) & $81.40 \pm 29.73$ & $77.51 \pm 39.74$ & 0.62 \\
\hline Systolic BP (Mean \pm SD ) & $119.16 \pm 39.50$ & $106.19 \pm 45.55$ & 0.17 \\
\hline Diastolic BP (Mean \pm SD) & $70.72 \pm 33.00$ & $63.09 \pm 34.15$ & 0.30 \\
\hline
\end{tabular}

* Students t-test is used for calculating $\mathrm{p}$ value

Heart rate, systolic \& diastolic Blood pressure are slightly lesser in group of patients with LBBB to that of RBBB which is statistically non-significant.

Table No.7 Duration of bundle branch block and relation with complications

\begin{tabular}{|l|l|l|l|l|}
\hline \multirow{2}{*}{ Duration } & \multirow{2}{*}{ Incidence } & \multicolumn{2}{l|}{ Complications } & \multirow{2}{*}{ P value } \\
\cline { 3 - 4 } & & No. & \% & \\
\hline 1-6 hr & 9 & 3 & 33.33 & 0.3173 \\
\hline 6-24 hr & 15 & 4 & 26.66 & 0.0707 \\
\hline 1-6 days & 7 & 3 & 42.85 & 0.705 \\
\hline Persistent until discharge & 56 & 23 & 41.07 & 0.18 \\
\hline Persistent until death & 13 & 13 & 100 & $0.0003^{*}$ \\
\hline
\end{tabular}

e definitions are given in methods and material.

\# $2^{\circ} / 3^{\circ} \mathrm{AV}$ block/VT/VF/cardiogenic shock/CCF/death

* statistically significant

Complication is noted more in BBB which is persistent, compared to transient blocks. It is found statistically significant that almost all patients who died, had BBB persistent until death. $(\mathrm{p}=0.0003)$.

Table No.8 Complications

\begin{tabular}{|c|c|c|c|c|c|c|c|c|c|c|}
\hline & \multicolumn{4}{|c|}{ RBBB $(n=69)$} & \multicolumn{4}{|c|}{ LBBB $(n=31)$} & \multirow[t]{3}{*}{ Total } & \multirow[t]{3}{*}{ p value } \\
\hline & \multicolumn{2}{|c|}{$\begin{array}{l}\text { AWMI } \\
(n=40)\end{array}$} & \multicolumn{2}{|c|}{ IWMI (n=29) } & \multicolumn{2}{|c|}{ AWMI $(n=31)$} & \multicolumn{2}{|c|}{$\begin{array}{l}\text { IWMI } \\
(n=0)\end{array}$} & & \\
\hline & No. & $\%$ & No. & $\%$ & No. & $\%$ & No. & $\%$ & & \\
\hline Cardiogenic shock & 9 & 22.5 & 6 & 20.68 & 8 & 25.80 & 0 & 0 & 23 & 0.14 \\
\hline Arrythmia\# & 4 & 10.0 & 5 & 17.25 & 5 & 16.12 & 0 & 0 & 14 & 0.28 \\
\hline $\begin{array}{l}\text { AV blocks } \\
\left(2^{\circ} / 3^{\circ}\right)\end{array}$ & 3 & 7.5 & 6 & 20.68 & 0 & 0 & 0 & 0 & 9 & $0.002^{*}$ \\
\hline
\end{tabular}


Acute Myocardial Infarction With Bundle Branch Block (Rbbb Or Lbbb) - Clinical ...

\begin{tabular}{|l|l|l|l|l|l|l|l|l|l|l|}
\hline Cardiac failure $^{\mathbf{e}}$ & 6 & 8.69 & 2 & 6.89 & 13 & 41.93 & 0 & 0 & 21 & 0.27 \\
\hline Mortality & 4 & 10.0 & 2 & 6.89 & 7 & 22.58 & 0 & 0 & 13 & 0.78 \\
\hline
\end{tabular}

* Statistically significant, $p$ values are calculated after comparing variables in group of RBBB to that of LBBB. \# APC/VPC/VT/VF

e definitions as given in methods and materials.

Mortality is seen in (13\%) of patients which comprises of $22.58 \%$ of LBBB patients and $8.69 \%$ of RBBB patients. Cardiogenic shock (23\%), cardiac failure (21\%), arrythmia (14\%) and high degree AV blocks $(9 \%)$ are seen in patients of MI with BBB. Mortality is seen in $22.5 \%$ of patients of AWMI with LBBB \& in $10 \%$ of patients of AWMI with RBBB. But mortality seen more in AWMI with LBBB followed by AWMI with RBBB.

It is found statistically significant that AV blocks are more common with RBBB than LBBB (p value 0.002).

Table No. 9 Mortality according to type of BBB

\begin{tabular}{|l|l|l|l|l|}
\hline \multirow{2}{*}{ Type } & Incidence & \multicolumn{2}{|l|}{ Observed mortality } & \multirow{2}{*}{ p value* } \\
\cline { 3 - 4 } & & No. & \% & \\
\hline RBBB isolated & 62 & 6 & 9.67 & \\
\hline RBBB+LAFB & 7 & 0 & 0 & \multirow{3}{*}{0.05} \\
\hline RBBB+LPFB & 0 & 0 & 0 & \\
\hline LBBB & 31 & 7 & 22.58 & \\
\hline
\end{tabular}

* Fisher's exact test two tailed p value.

Mortality is more with LBBB, found in 7 patients out of 31 patients (22.58\%) followed by RBBB which is in 6 patients out of 62 patients $(9.67 \%)$. This finding is statistically not significant.

Table No. 9 Correlation of In-hospital mortality to Type of bundle branch block

\begin{tabular}{|l|l|l|l|}
\hline \multirow{2}{*}{ Incidence } & Mortality & $\%$ \\
\cline { 3 - 4 } & & No. & 0 \\
\hline Transient BBB & 31 & 0 & 18.84 \\
\hline Permanent BBB & 69 & 13 & \multicolumn{2}{l}{} \\
\hline Fisher's exact test two tailed p value $=0.0082^{*}$
\end{tabular}

* Statistically significant

In hospital mortality is seen almost exclusively in patients having permanent BBB compared to transient BBB which is statistically significant $(\mathrm{p}=0.0082)$.

Table No. 10 Correlation of In-hospital mortality to Type of MI with bundle branch block

\begin{tabular}{|l|l|l|l|}
\hline & Incidence & Mortality & \\
\cline { 3 - 4 } & & No. & \% \\
\hline Anterior MI with RBBB & 40 & 4 & 10 \\
\hline Inferior MI with RBBB & 29 & 2 & 6.89 \\
\hline Anterior MI with LBBB & 31 & 7 & 22.58 \\
\hline Fisher's exact test two tailed p value 0.2105 & \multicolumn{3}{|l}{} \\
\hline
\end{tabular}

Anterior wall MI with LBBB is associated with higher mortality compared to other infarct, which is statistically non significant.

\section{Discussion}

The present study is conducted in Department of Medicine, G.R. Medical College \& J.A. Group of Hospitals, Gwalior (M.P.) with an aim to study clinical characteristics in patients of acute coronary syndrome with bundle branch block and its short term prognostic significance by means of development of various complications or in hospital mortality.

Age:

The mean age of patients was $60.19 \pm 13$ years. Escoteguy et $\mathrm{al}^{19}$ in 1992 studied the bundle branch \& AV block as complications of acute MI in thrombolytic era, and mean age of studied population was $59.9 \pm 15.2$ years. Newby et $\mathrm{al}^{13}$ studied incidence of BBB in patients treated with thrombolytic therapy and mean age was 63.60. Abidov et $\mathrm{al}^{14}$ studied the influence of conduction disturbance on acute MI, mean age of study was 61.70 . Hindman et $\mathrm{al}^{6}$ studied the clinical significance of BBB complicating acute MI, mean age of study was $65 \pm 12$. Sgarbossa et $\mathrm{al}^{15}$ studied the acute MI with BBB on hospital admission with mean age group 69.54. MelgarejoMoreno et $\mathrm{al}^{16}$ studied the BBB in acute MI with mean age years $67.7 \pm 10.1$. The age group of patients in our study is similar to that of Escoteguy et al study. Rest of the studies also have the age of 6th decade mostly. In 
our study it is found statistically significant that females are older (mean age 64.83 \pm 8.77 ) than males (mean age 58.72 \pm 13.22 ).

Gender : In the present males are 74 and females 26. On comparing with other studies, Sgarbossa et $\mathrm{al}^{15}$ study had $75 \%$ males \& $25 \%$ females. Newby et al ${ }^{13}$ study had $71.1 \%$ males \& $24 \%$ females. MelgaregoMoreno et al ${ }^{16}$ studied significance of BBB in acute MI and had $68 \%$ males \& $32 \%$ females. Hindman et al ${ }^{6}$ study had $65 \%$ males \& $45 \%$ females. The general distribution of our study is similar to that of Sgarbossa et al study.

Site of infarct :In our study blocks involving the BBB were more common in anterior infarction (table 7) but blocks at the atrioventricular node occurred predominantly in inferior infarction (table 13). This association was statistically significant $(\mathrm{p}<0.001)$. This finding in our study is consistent with a study by Majumder et al $^{17}$ carried out in Bangladesh. He found strong association of AV blocks with inferior MI and that of BBB with anterior MI, hence concluded that conduction defects were associated with increased rate of complications \& death.

\section{Type of BBB:}

In our study RBBB was present in $69 \%$ of patients \& LBBB $31 \%$ patients which is found to be statistically significant $(\mathrm{p}=0.0001)$. On comparing with other studies. Melagarejo-Moreno et al ${ }^{16}$ documented $76 \%$ RBBB \& $24 \%$ LBBB patients. The lower value of our study, than this study may be because Moreno et

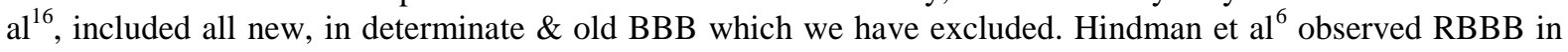
$62 \%$ of patients \& LBBB in $38 \%$ of patients. The value of our study are slightly higher but in nearly similar proportion to this study. Our values are very similar to study in Hero-2 trial by Wong et al ${ }^{18}$, which documented $\mathrm{RBBB}$ in $66 \%$ and $\mathrm{LBBB}$ in $34 \%$.

\section{Duration of BBB:}

We found $31 \%$ of patients had transient BBB, while permanent in $56 \%$ of patients \& $13 \%$ of patients had persistent until death. We found it statistically significant that all patients who died of BBB persistent until death $(\mathrm{p}=0.003)$. Rate of $12-30 \%$ of transient BBB referred in prethrmobolytic studies like

Godman et $\mathbf{a l}^{\mathbf{2}}$ who studied complete BBB complicating acute MI. Moreno et al ${ }^{\mathbf{1 6}}$ reported rate of $53 \%$ transient BBB a value higher than our figure. The difference in values of our study and others may be because of the differences in rate of thrombolysis. Transient blocks are found more in patients who undergoes thrombolysis, but almost $50 \%$ of our patients could not be thrombolysed as most of our patients are rural patients who takes longer time to reach tertiary centre and also their affordability for thrombolytic drug is limited.

\section{BBB \& in hospital complications :}

AV blocks Total 18 patients of AV block are found complicating in our study out of which 9 were $1^{0}$ and 9 of high degree $\left(2^{0}-4\right.$ patients and $3^{0}-5$ patients). No AV block was found with LBBB but 3 blocks were found with anterior MI with RBBB (16.6\%) \& 15 with inferior MI with RBBB (83.3\%). The presence of AV block with inferior wall MI compared to anterior wall MI is found to be statistically significant ( $\mathrm{p}=0.0047)$. Out of 5 complete AV block 2 patients accompanying those with inferior wall MI died, and 1 patient who developed complete AV block in anterior MI, could not be followed up after left hospital only with 1 day of stay. Hence, the mortality rate due to AV block was 2 out of 5 (40\%).

On comparing with other studies, Hindman et $\mathrm{al}^{6}$ study shows incidence of AV block during MI was $22 \%$ which is closer to our figure. Muhammad Asif Bhalli et al ${ }^{20}$ study reported BBB with complete AV block in $6.5 \%$ of patients which is again closer to our study which shows it in $5 \%$ of patients. While studying mortality in patients with $3^{0}$ block with BBB Bates ER et al ${ }^{21}$ found $20 \%$ mortality rate and Beher S et al ${ }^{22}$ documented $37 \%$ mortality rate. Goldberg RJ et $\mathrm{al}^{23}$ documented $41.9 \%$ of mortality rate in patients with complete heart block with $\mathrm{BBB}$, which is closer to our value of $40 \%$ of mortality. Cardiogenic shock, cardiac failure and arrhythmia

In our study cardiogenic shock found in $23 \%$ of patients. Out of that $21.73 \%$ in patients of RBBB \& $25.8 \%$ in patients of LBBB. In RBBB incidence was found more in anterior compared to inferior location $(22.5 \%$ vs. $20.68 \%)$ which is statistically non significant. Out of total in hospital mortality of 13 patients, 7 patients died because of cardiogenic shock $(30.43 \%)$ which is statistically non significant.

Arrhythmia (SVT/VT/VF) complicating patients of BBB was found in 14 patients out of which 9 patients had VT/VF. 2 out of these 9 patients died (22.22\% mortality rate) which is found to be statistically non significant. Cardiac failure in patients of $\mathrm{MI}$ with $\mathrm{BBB}$ on admission and during their stay in hospital was found in 21 patients, out of that 8 patients of $\operatorname{RBBB}(39 \%)$ and in 13 patients of LBBB $(61 \%)$ which is statistically found to be non significant. This similar finding is seen in study done by Melgarejo-Moreno et $\mathrm{al}^{16}$, which 
documented cardiac failure in $40 \%$ of patients of RBBB and $64 \%$ of LBBB but this is found to be statistically non significant. In our study 37 patients were having Killip class $>1$ on admission, out of which 12 patients died compared to 1 mortality out of 63 patients of Killip class 1 . It is found to be statistically extremely significant ( $p$ value $<0.0001$ ). Similar finding is found in GUSTO-1 study by Sgarbossa et $\mathrm{al}^{15}$. This confirms the higher incidence of cardiac failure in patients of BBB along with mortality and also suggest that Killip class remained a powerful prognostic factor for mortality. Moreno et $\mathrm{a}^{16}$ study had killip class $>1$ in $46 \%$ of patients, $40 \%$ in patients of RBBB \& $64 \%$ in patients of LBBB which was statistically significant .

\section{Conclusion}

The occurrence of bundle branch block in acute myocardial infarction is important because it indicates that infarction may be extensive and may result in cardiac failure or death; however, the presence of bundle branch block is also important because it indicates seriously jeopardized AV conduction which could result in sudden extremely slow heart rates or asystolic arrest. The patients of acute MI with bundle branch block presenting to coronary care unit with cardiogenic shock and Killip class $>1$ should be attended and managed aggressively, as presence of cardiogenic shock and Killip class $>1$ on admission in these patients is associated with greater mortality. The presence of co-morbid conditions like past history of myocardial infarction, diabetes mellitus, hypertension and presence of poor vital parameters on admission in these patients are indicators of poor prognosis.

\section{Bibliography}

[1]. Bauer Ge, Julian Dg, Valentine Pa: Bundle branch block in acute myocardial infarction. Br Heart J 27: 724, 1965

[2]. Godman MJ, Lassers BW, Julian DG: Complete bundle-branch block complicating acute myocardial infarction. N Engl J Med 1970;282:237-240

[3]. Noms RM, Coxson MS: Bundle-branch block in acute myocardial infarction. Am Heart J 1970;79:72\&733

[4]. Atkins JM, Leshin SJ, Blomqvist G, Mullins CB: Ventricular conduction blocks and sudden death in acute myocardial infarction. Potential indications for pacing. N Engl J Med 1973;288:28 1-284

[5]. Nimetz AA, Shubrooks SJ, Hutter AM, DeSantis RW: The significance

[6]. of bundle-branch block during acute myocardial infarction. Am Heart J 1975;90:439-444

[7]. Hindman MC, Wagner GS, Jar0 M, Atkins JM, Sheinman MM, DeSanctis RV, Hutter AH, Yeatman L, Rubenfire M, Pujura C, Rubin M, Moms JJ: The clinical significance of bundle-branch block complicating acute myocardial infarction. I. Clinical characteristics, hospital mortality, and one-year follow-up. Circulation 1978;58:679-688

[8]. Steinmetz E, Haghfelt T, Thygesen K: Incidence and, prognostic significance of intraventricular block in acute myocardial infarction. Cardiology 1979;64:280-288

[9]. Hollander G, Nadiminti V, Lichstein E, Greengart A, Sanders M: Bundle-branch block in acute myocardial infarction. Am Heart J $1983 ; 105: 738-743$

[10]. Klein RC. Vera Z, Mason DT Intraventricular conduction in acute myocardial infarction. Incidence, prognosis, and therapy. Am Heart J I984;108: 1007-1013.

[11]. Opolski G, KraskaT, Ostrzycki A, Zielinski T, Korewicki J: The effectof infarct size on atrioventricular and intraventricular conduction disturbances in acute myocardial infarction. In? J Cardiol 1986; 10: 141-147

[12]. Go AS, Barron HV, Rundle AC, Ornato JP, Avins AL, for the NationalRegistry of Myocardial Infarction 2 Investigators: Bundlebranch block and in-hospital mortality in acute myocardial infarction. Ann Intern Med 1988;129:690-697

[13]. Dubois C, PiCrard LA, Smeets JP, Foidart G, Legrand V, Kulbertus HE: Short- and long-term prognostic importance of complete bundle-branch block complicating acute myocardial infarction. Clin Cardiol1988;11:292-296

[14]. Newby KH, Pisano E, Krucoff Mw, Green C, Natale A: Incidence and clinical relevance of the occurrence of bundle-branch block in patients treated with thrombolytic therapy. Circulation 1996;94: 2424-2428

[15]. Abidov A, Kaluski E, Hod H, LeorJ, Vered Z, Gottliebs Becher et al. Influence of conduction disturbance on clinical outcome in patients with Acute Myocardial Infarction receiving thrombolysis (results from ARGAMI-2 study). Am J Cardiol 2004; 93: 76-80

[16]. Sgarbossa EB, Pinski SL, Topol EJ, Califf RM, Barbagelata A, Goodman SG et al. Acute Myocardial Infarction and Complete Bundle Branch Block at Hospital Admission: Clinical Characteristics and Outcome in the Thrombolytic Era. GUSTO-I Investigators. J Am Coll Cardiol 1998; 21(1): 105-10.

[17]. Moreno AM, Thomas GJ, Alberola GA. Prgnostic significance of bundle branch block in Acute Myocardial Infarction. The importance of location and time of appearance. Clin Cardiol 2001; 24(5): 371-76

[18]. Majumder AA, Malik A, Zafar A. Conduction disturbances in acute myocardial infarction: Incidence, site-wise relationship and the influence on in-hospital prognosis. Bangladesh Med Res Counc Bull.1996;22:74-80.

[19]. Wong C-K, Stewart RAH, Gao W, French JK, Raffel OC, White HD, for the Hirulog and Early Reperfusion or Occlusion (HERO2) Trial Investigators. Prognostic differences between different types of bundle branch block during the early phase of acute myocardial infarction: insights from the Hirulog and Early Reperfusion or Occlusion (HERO)-2 trial. Eur Heart J 2006;27:21-28.

[20]. Escosteguy CC, Carvalho Mde A, Medronho Rde A, Abreu LM, Monteiro Filho MY. Bundle branch and atrioventricular block as complications of acute myocardial infarction in the thrombolytic era. Arq Bras Cardiol 2001;76:291-6.

[21]. Bhalli M.A., Khan M.Q., Samore N.A. et al Frequency And Clinical Outcome In Conduction Defects In Acute Myocardial Infarction. J Ayub Med Coll Abbottabad 2009;21(3)

[22]. Bates ER, Califf RM, George BS, Lee KL, Topol EJ, Aronson L et al. Complete Atrioventricular block complicating inferior wall acute MI treated with reperfusion therapy. Am J Cardiol 1991; 67:225-30

[23]. Beher S, Zissman E, Zion M, HOD H, Shalev Y, Capsi A, Kaplinsky et al. Complete Atrioventricular block complicating inferior wall acute MI: Short and long term prognosis. Am Heart J 1993; 125: 1622-6

[24]. Goldberg RJ, Zevallos JC, Alpert JS, Gore JM, Chen Zuoyao, Dalen JE et al. Prognosis of Acute MI complicated by complete Heart block (The Worcester Heart attack study). Am J Cardiol 1992; 69: 1135-41. 